\title{
Review
}

\section{Post-Stroke Fatigue: Epidemiology, Clinical Characteristics and Treatment}

\author{
Monica Acciarresi ${ }^{a} \quad$ Julien Bogousslavsky ${ }^{b}$ Maurizio Paciaroni ${ }^{a}$ \\ ${ }^{a}$ Stroke Unit and Division of Cardiovascular Medicine, University of Perugia, Perugia, Italy; ${ }^{\mathrm{b}}$ Neurocenter, \\ Genolier Swiss Medical Network, Clinique Valmont, Glion/Montreux, Switzerland
}

\section{Key Words}

Fatigue $\cdot$ Stroke $\cdot$ Depression · Asthenia

\begin{abstract}
Fatigue is a disabling and persistent symptom affecting many stroke survivors and is a predictor for death after stroke onset. Post-stroke fatigue is a multidimensional motor-perceptive, emotional and cognitive experience that has become of interest for stroke researchers only in the recent past. More studies are still needed to understand the pathophysiology, clinical characteristics, associated factors and best treatment strategy. The aim of this narrative review was to provide a comprehensive knowledge, from current literature, regarding the epidemiology, clinical characteristics and treatment of fatigue in order to provide physicians with better tools for treating this debilitating symptom that worsens outcome.
\end{abstract}

(c) 2014 S. Karger AG, Basel

\section{Introduction}

Post-stroke fatigue is described as 'a feeling of early exhaustion with weariness, lack of energy and aversion to effort that develops during physical or mental activity and is usually not ameliorated by rest' [1].

\section{KARGER}

E-Mail karger@karger.com www.karger.com/ene
Fatigue is a multidimensional motor-perceptive, emotional and cognitive experience [2].

Fatigue can be classified as either objective or subjective; objective fatigue is defined as the observable and measurable decrement in performance occurring with the repetition of a physical or mental task, while subjective fatigue is a feeling of early exhaustion, weariness and aversion to effort [3].

Post-stroke fatigue is generally thought to be a primary fatigue, but many researchers have proposed several contributing factors specific to post-stroke fatigue, such as de-conditioning, physical impairment, disuse, sleep disorders, medications side effects and depression [4].

\section{Methods}

A computer-aided search in Medline was performed on June 6, 2013, which was later updated in October 2013 using the keywords 'fatigue', 'stroke', 'depression', 'asthenia'.

The search retrieved 69 publications. Two authors read every abstract and obtained the full text of paper that were deemed interesting; reference lists of the retrieved articles were scrutinized for potentially relevant studies.

We excluded case reports, abstracts as well as articles not written in English and articles not published in peer- 
reviewed journals. Moreover, we also excluded studies having a few patients enrolled.

Overall, 62 articles were read by the three authors in order to provide a narrative review of the epidemiology, clinical characteristics and treatment for post-stroke fatigue.

\section{Epidemiology}

Fatigue is among the most prevalent symptoms after stroke and is an important predictor for death after stroke onset [5]. The frequency of post-stroke fatigue ranges from $29 \%$ to $77 \%$ [5-9]. This large variability across studies is due to two known reasons. The first reason is that fatigue is difficult to define, characterise and measure [10]. In fact, methodological differences among studies include different definitions of fatigue, different inclusion criteria and different fatigue scales $[2,11]$.

No scales have been developed specifically for measuring fatigue after stroke. The most frequently used instruments for evaluating fatigue include the Fatigue Severity Scale (FSS), SF-36/12 (vitality subscale), the Profile of Mood States (POMS), the Fatigue Assessment Scale (FAS), and the Multidimensional Fatigue Symptom Inventory (MFIS). Of these, FSS is the most frequently used in stroke studies due to its high internal consistency. All of the scales lack a cut-off point. In this way it is difficult to determine the absolute degree of prevalence [9].

Second, these diverse levels of prevalence have been most likely due to the varying times of assessment. Yet, even in this context, data are scarce and contradictory. Christensen et al. [11] reported pathological fatigue in 59, 44,38 and $40 \%$ of stroke patients at 10 days, 3 months, 1 and 2 years respectively, following the onset of stroke. Another study, found that the prevalence of post-stroke fatigue was 35\% two months after stroke and 33\% at 1.5 years post-stroke [12]. Radman et al. [13] reported similar results after 6 and 12 months following a minor stroke: 30.5 and $34.7 \%$, respectively. Another longitudinal study showed an increased percentage of self-rated fatigue at admission as well as 6-month and 1 -year follow-ups; 51.5 , 64.1 and $69.5 \%$, respectively [14].

\section{Clinical Characteristics}

Descriptions of pathological fatigue have included different dimensions of the phenomenon, with problems related to self-control and emotional instability, reduced mental capacity and perceived reduction in energy needed for daily activities such as reading and participating in physical or social activities [7]. It is generally qualitatively different from the fatigue experienced before stroke and can be exacerbated by stress and physical exercise, and responds well to rest, sleep and low temperature [2]. This type of fatigue is more commonly known as exertion fatigue. Exertion fatigue is acute in nature, with a rapid onset, short duration and short recovery period [15], commonly experienced after intense physical exertion or use of mental effort $[16,17]$. Other described subtypes of fatigue include mental fatigue and psychological fatigue. Mental fatigue appears with cognitively demanding tasks, while psychological fatigue is associated with lack of interest or poor motivation [3]. These subtypes of fatigue are not mutually exclusive; if exertion fatigue is more prevalent in patients with stroke, mental or psychological fatigue is more prevalent in patients with other neurological diseases including multiple sclerosis $[2,18]$.

Indeed, Tseng et al. [15] reported that aerobic fitness and depression are strong independent predictors of exertion fatigue and chronic fatigue in post-stroke, respectively suggesting that exertion fatigue and chronic fatigue are distinct.

\section{Predisposing and Associated Factors}

\section{Stroke Type, Stroke Side and Stroke Location}

Associations between fatigue and stroke features remain controversial.

Moreover, the claim on the part of the patients that fatigue after stroke is unlike anything ever experienced before [19], supports the idea that there may be an underlying association between fatigue and brain lesion size and its location.

Some studies have reported no relationship between fatigue and stroke location or fatigue and stroke type $[5$, $7,8,11,13,20-26]$. A study has reported a relationship between the number of strokes and fatigue, reporting a lower proportion of fatigue among patients who had a first stroke compared with those having recurrent strokes [5].

Regarding pathological type of stroke and fatigue, only one study in literature has reported that fatigue is more severe after ischaemic stroke than after intracerebral haemorrhage [27].

Conversely, studies have suggested an association between post-stroke fatigue and stroke side and location. In 
a study in patients with minor infarct, there was no observed correlation between infarct and fatigue severity scores, except for a tendency toward left parietal lesions [13].

Tang et al. [28] found that fatigue after stroke has been associated with acute infarcts in the basal ganglia and internal capsule detected on MRI, whereas Snaphaan et al. [12] observed that fatigue after stroke has been more common in patients with infratentorial lesions detected on either CT or MRI. Similar findings have been reported by two studies observing a relationship between fatigue and lesions in the posterior circulation territory, defined as either brainstem or thalamic stroke [29] basilar artery infarction [26]. In this regard, a recent study [22] even if it revealed no CT predictors for fatigue at 1 month after stroke, using the OCSP classification [30] as an alternative indicator of lesion location, indicated that patients with POCS had higher fatigue scores that those with other subtypes. Some authors have hypothesised that damage to the ascending reticular activating system in the brainstem may lead to mild impairment in arousal, changes in attention and subsequent development of fatigue [1], whereas others have supposed that the disruption of serotoninergic pathways in the brainstem is another potential mechanism of fatigue after stroke [31].

\section{Neuroradiologic Findings}

Even if a study comparing the severity of cerebral atrophy and white matter lesions in patients with or without fatigue after stroke did not report any association [12], a recent study has described that severe leucoaraiosis on CT was predictive for developing fatigue 1 year after haemorrhage [32]. Likewise, Naess et al. [33] have reported that the presence of leucoaraiosis on CT was independently associated with post-stroke fatigue in patients with ischaemic or haemorrhagic injury. These findings are consistent with the hypothesis that neuroanatomical changes may play a role in the development of fatigue.

\section{Motor Recovery and Residual Disability}

Patients who feel that they have not made a full recovery are significantly more likely to be fatigued than those who make a full recovery. However, in patients with excellent neurological and neuropsychological recovery, as in patients with minor stroke or TIA, post-stroke fatigue may be the only persisting sequela, which may severely limit a complete recovery of their previous level of functioning. Even if the prevalence of fatigue after a minor stroke is usually higher than after TIA, fatigue can also be present after a transient neurological deficit. In these cases, the influence of additional depressive and anxious factors on the impact of fatigue should be addressed [1]. However, Winward et al. [34] have described that patients with minor stroke reported significantly higher levels of fatigue at 6-month follow-up than those with TIA and this difference was independent of measured potential confounders for fatigue, including anxiety, depression, recent life events, relevant blood tests, and medication; this suggests that an excess of fatigue in patients with minor stroke indicates a causal association between fatigue and cerebrovascular accident. Although fatigue can be related to increased physical efforts associated with severe neurological deficits, the presence of fatigue in stroke patients with little or no motor deficit suggests that this excess of fatigue, compared with TIA patients, is most likely attributable to central mechanisms.

Functional neuroimaging studies have reported that physical activity is associated with activation of the prefrontal brain as well as the insula and anterior cingular cortex [35]. These areas have been implicated in the development of tiredness after stroke [36]. Thus, physical activity, by activating the prefrontal circuits, may improve attention and therefore reduce fatigue. One plausible model for post-stroke fatigue is that reduced physical activity after stroke leads to physical de-conditioning and in turn exertional fatigue (neuromuscolar fatigue), which then is responsible for the avoidance of physical activity, contributing to the development of chronic ( $\operatorname{cog}$ nitive) fatigue [37].

There are multiple underlying mechanisms by which exercise may improve post-stroke fatigue: exercise can increase the cerebral blood flow bay by activating the sympathetic nervous system, whereas on a molecular level, it is thought to change the functioning of neurotransmitters, which has been suggested for its role in the development of fatigue $[38,39]$.

\section{Depression}

A strong relationship between depression and poststroke fatigue has been described and the presence of fatigue indeed constitutes one of the criteria for depression in most scales [3]. Moreover, depression is considered one of the most critical concomitant post-stroke symptoms associated with fatigue, making it difficult to differentiate between them as independent conditions.

In a study [40] of 200 Italian patients with first-ever stroke surveyed for depression three months after their stroke, their scores for fatigue or loss of energy tended to be significantly higher among patients who had a minor 
depressive disorder compared to those without any depressive disorder. Similar findings were found in a Belgian study [41] that reported that reduced appetite, psychomotor retardation, and fatigue contributed significantly to identifying patients who had post-stroke depression. Likewise, a relationship between depression and high levels of fatigue has been reported in several other studies [ 5 , 8, 26, 42, 43]. Carlsson et al. [7] concluded that the odds ratio for having fatigue one year after stroke in the presence of depression, was 3.2 (95\% confidence interval: $1.7-$ $6.0)$.

However, post-stroke fatigue can also occur in the absence of depression, with the latter found to be independent of fatigue in stroke survivors [20,21]. Van der Werf et al. [6] found that only $38 \%$ of patients with severe fatigue were also depressed. Ingles et al. [20] reported similar findings with $29 \%$ of patients having both symptoms.

\section{Cognitive Impairment}

Cognitive impairment has been found to worsen fatigue after subarachnoid haemorrhage $[44,45]$ and brain injuries; nonetheless, this association has received little attention. Additionally, in a sub-study on quality of life of the International Stroke trial, Mead and colleagues found that a worse mental health score and worse emotional role function measured with SF-36 and increasing age were significantly associated with fatigue [23]. Conversely, a long-term study [26] has reported no association between fatigue and cognitive impairment, but this result could be explained by the fact that they used only the Mini-Mental State Examination, which does not assess attention or executive function.

Gender

Several studies of fatigue in general population have reported a higher proportion of fatigue among women [46-48]. However, there is conflicting evidence on a relationship between gender and post-stroke fatigue. In fact, some researchers have suggested that there are no differences between the sexes [12, 25, 26], while some other studies have reported a higher proportion of post-stroke fatigue among women $[20,22,23]$. This sex disparity could be explained by endocrine and stress-related factors.

\section{Time Course of Fatigue and Influence on Outcome}

In a Danish study [11] analysing the course of fatigue over a two-year follow-up after first-ever stroke, the poststroke fatigue level was seen to decrease during the first three months after hospital discharge. This situation re- mained unchanged for the next 2 years of follow-up. Different findings have come from a study by Schepers et al. [8] who have reported an increase in the prevalence of fatigue during the first year after stroke. This difference could have been explained by the high prevalence of depression in the Schepers's study, which could have influenced the time course of fatigue.

Regarding the duration of pathological fatigue after stroke, this could become chronic and be present several years after stroke onset-up to $40 \%$ after two years [11].

The initial level of fatigue is the main determinant of increasing fatigue over time [9] and this being the case, targeting fatigue soon after stroke can help in preventing its persistence.

Several studies have reported that post-stroke fatigue is an independent predictor of shorter survival $[5,23]$, institutionalization $[5,21]$, poorer functional outcome [11] and greater dependency for activities of daily living (ADLs) and instrumental activities of daily living (IADLs) [43]. Moreover, in young patients, fatigue appears to be a determinant of not being able to resume paid work following stroke, independently of physical disability or cognitive deficit [49].

\section{Treatment}

Fatigue following stroke is a multidimensional symptom and may have several causative factors. Currently, there are no evidence-based interventions that can successfully prevent and treat post-stroke fatigue. However, pharmacological, physical and psychological treatments are used to alleviate fatigue. Furthermore, environmental suggestions can also provide benefit. A multidisciplinary approach that targets both the physical as well as the cognitive aspects of fatigue is needed [50].

\section{Pharmacological Treatment}

Even if depression and fatigue are commonly dissociated and sometimes anxiety and depression are known to be consequences rather than causative factors of fatigue, anti-depressant or counselling may address the mental aspects of fatigue [51].

Choi-Kwon et al. [42] evaluated the therapeutic effects of fluoxetine $20 \mathrm{mg} /$ day on fatigue and other emotional disturbances in a placebo-controlled, double-blind trial including 83 outpatients with post-stroke emotional disturbances, at a mean of 14 months after stroke onset. Fatigue was evaluated by the Fatigue Severity Scale (FSS) and the Visual Analogue Scale (VAS) at baseline, three 
months and six months after the start of treatment. Fluoxetine resulted being ineffective on fatigue after stroke, but it seemed to decrease depressive symptoms, suggesting that serotoninergic system dysfunction is not a potential mechanism for post-stroke fatigue.

Treatment of pain may help patients because it allows for the participation in exercises and improves mood disturbance related to pain [51].

Sleep disturbances are coexisting symptoms of poststroke fatigue, as reported in various studies $[25,52,53]$. In some of these individuals, sleep apnea has been diagnosed. However, an improvement in sleep disordered breathing (with a CPAP) does not seem to be effective in relieving post-stroke fatigue, unless accompanied by symptomatic sleep apnea syndrome [54].

\section{Physical Treatment}

Graded physical activity programs have been suggested for their contribution to the treatment of post-stroke fatigue. This is based upon the fact that exercise improves both physical and functional outcomes and therein reduces fatigue; as has been reported for medical conditions including cancer and multiple sclerosis [55-58].

Observational studies of stroke patients have reported that most patients are inactive during their hospital stays in both acute and rehabilitation wards. For these patients, graded physical activity programs have been recommended in order to help them gradually increase physical strength without aggravating distressing symptoms [59].

A cross-sectional study has reported that higher levels of fitness (measured using a maximal effort graded exercise test (V02 peak) using a stepping ergometer) were significantly associated with less exertion fatigue $(\mathrm{p}<0.01)$; in the absence of an association between fitness and chronic fatigue [15].

A recent multicenter, randomized, controlled trial has indicated that a graded activity training programme plus cognitive therapy over a 12 -week period leads to a greater reduction in persistent post-stroke fatigue compared to cognitive therapy alone. This reduction has been reported to remain stable at 6 month-follow-up producing an overall better functional health status, characterized by fewer symptoms of depression, and improvements in both sleep and physical endurance [44].

\section{Psychological Treatment}

Cognitive compensation strategies that circumvent the limited energetic resources available to patients suffering from post-stroke fatigue might also be beneficial.
These compensation strategies require enhanced planning and variation of activities to foster a more regular pattern of activities and rest [60]. An augmented form of cognitive behavioural therapy, as that proposed by Broomfield et al. [61] for post-stroke depression, is a good starting point for addressing these issues. These therapies take into account cognitive deficits and therefore might aid in fostering the behavioural changes needed to apply compensation strategies.

\section{Environmental Suggestions}

Environmental suggestions for improving in-hospital fatigue include regular access to fresh air, a home-like environment, good personal attention as well as access to communicative vehicles such as television, Internet and ward activities [62]. Many patients have reported disturbed sleep while in hospital due to hospital rhythms. Changes in the hospital living conditions could improve fatigue post-stroke.

Out-of-hospital recommendations include [51]: the encouragement of physical activity, proper nutrition, as well as adequate rest and relaxation.

\section{Conclusions}

Post-stroke fatigue is a common, complex, multi-factorial syndrome that is poorly understood regarding its pathophysiology, clinical characteristics and associated factors. Our review has found that there is a paucity of studies that have examined and sought to determine new intervention strategies for post-stroke fatigue. This indicates that currently there is a low level of attention paid to a post-stroke symptom, which is experienced by most post-stroke patients, greatly reducing the quality of life.

References

1 Staub F, Bogousslavsky J: Fatigue after stroke: a major but neglected issue. Cerebrovasc Dis 2001;12:75-81.

$\longrightarrow 2$ Annoni J-M, Staub F, Bogousslavsky J, Brioschi A: Frequency, characterisation and therapies of fatigue after stroke. Neurol Sci 2008 ; 29(suppl 2):S244-S246.

-3 Staub F, Bogousslavsky J: Post-stroke depression or fatigue. Eur Neurol 2001;45:3-5.

-4 De Groot MH, Phillips SJ, Eskes GA: Fatigue associated with stroke and other neurologic conditions: implications for stroke rehabilitation. Arch Phys Med Rehabil 2003;84:17141720.

5 Glader E-L, Stegmayr B, Asplund K: Poststroke fatigue: a 2-year follow-up study of stroke patients in Sweden. Stroke 2002;33:1327-1333. 
6 Van der Werf SP, van den Broek HL, Anten HW, Bleijenberg G: Experience of severe fatigue long after stroke and its relation to depressive symptoms and disease characteristics. Eur Neurol 2001;45:28-33.

7 Carlsson GE, Möller A, Blomstrand C: Consequences of mild stroke in persons $<75$ years - a 1-year follow-up. Cerebrovasc Dis 2003; 16:383-388.

8 Schepers VP, Visser-Meily AM, Ketelaar M, Lindeman E: Poststroke fatigue: course and its relation to personal and stroke-related factors. Arch Phys Med Rehabil 2006;87:184188.

9 Lerdal A, Bakken LN, Kouwenhoven SE, et al: Poststroke fatigue - a review. J Pain Symptom Manage 2009;38:928-949.

10 Aaronson LS, Teel CS, Cassmeyer V, et al: Defining and measuring fatigue. Image J Nurs Sch 1999;31:45-50.

-11 Christensen D, Johnsen SP, Watt T, Harder I, Kirkevold M, Andersen G: Dimensions of post-stroke fatigue: a two-year follow-up study. Cerebrovasc Dis 2008;26:134-141.

$\checkmark 12$ Snaphaan L, van der Werf S, de Leeuw F-E: Time course and risk factors of post-stroke fatigue: a prospective cohort study. Eur J Neurol 2011;18:611-617.

-13 Radman N, Staub F, Aboulafia-Brakha T, Berney A, Bogousslavsky J, Annoni J-M: Poststroke fatigue following minor infarcts: a prospective study. Neurology 2012;79:14221427.

14 Van Eijsden HM, van de Port IGL, VisserMeily JMA, Kwakkel G: Poststroke fatigue: who is at risk for an increase in fatigue? Stroke Res Treat 2012;2012:863978.

-15 Tseng BY, Billinger SA, Gajewski BJ, Kluding PM: Exertion fatigue and chronic fatigue are two distinct constructs in people post-stroke. Stroke 2010;41:2908-2912.

-16 Tiesinga LJ, Dassen TW, Halfens RJ, van den Heuvel WJ: Factors related to fatigue; priority of interventions to reduce or eliminate fatigue and the exploration of a multidisciplinary research model for further study of fatigue. Int J Nurs Stud 1999;36:265-280.

$\checkmark 17$ Jensen S, Given B: Fatigue affecting family caregivers of cancer patients. Support Care Cancer 1993;1:321-325.

18 Vercoulen JH, Hommes OR, Swanink CM, et al: The measurement of fatigue in patients with multiple sclerosis. A multidimensional comparison with patients with chronic fatigue syndrome and healthy subjects. Arch Neurol 1996;53:642-649.

19 Flinn NA, Stube JE: Post-stroke fatigue: qualitative study of three focus groups. Occup Ther Int 2010;17:81-91.

20 Ingles JL, Eskes GA, Phillips SJ: Fatigue after stroke. Arch Phys Med Rehabil 1999;80:173178.

-21 Choi-Kwon S, Han SW, Kwon SU, Kim JS: Poststroke fatigue: characteristics and related factors. Cerebrovasc Dis 2005;19:84-90.

22 Kutlubaev MA, Shenkin SD, Farrall AJ, et al: $\mathrm{CT}$ and clinical predictors of fatigue at one month after stroke. Cerebrovasc Dis Extra 2013;3:26-34.

23 Mead GE, Graham C, Dorman P, et al: Fatigue after stroke: baseline predictors and influence on survival. Analysis of data from UK patients recruited in the International Stroke Trial. PLoS One 2011;6:e16988.

24 Leegaard OF: Diffuse cerebral symptoms in convalescents from cerebral infarction and myocardial infarction. Acta Neurol Scand 1983;67:348-355.

25 Appelros P: Prevalence and predictors of pain and fatigue after stroke: a populationbased study. Int J Rehabil Res 2006;29:329333.

26 Naess H, Nyland HI, Thomassen L, Aarseth J, Myhr K-M: Fatigue at long-term follow-up in young adults with cerebral infarction. Cerebrovasc Dis 2005;20:245-250.

27 Naess H, Lunde L, Brogger J, Waje-Andreassen U: Post-stroke pain on long-term followup: the Bergen stroke study. J Neurol 2010; 257:1446-1452.

28 Tang WK, Chen YK, Mok V, et al: Acute basal ganglia infarcts in poststroke fatigue: an MRI study. J Neurol 2010;257:178-182.

29 Staub F, Annoni JM, Bogousslavsky J: Fatigue after stroke: a pilot study. Cerebrovasc Dis 2000;10(suppl):62.

30 Pittock SJ, Meldrum D, Hardiman O, Thornton J, Brennan P, Moroney JT: The Oxfordshire Community Stroke Project classification: correlation with imaging, associated complications, and prediction of outcome in acute ischemic stroke. J Stroke Cerebrovasc Dis $2003 ; 12: 1-7$.

31 Kutlubaev MA, Duncan FH, Mead GE: Biological correlates of post-stroke fatigue: a systematic review. Acta Neurol Scand 2012;125: 219-227.

32 Rossi C, Cordonnier C, Popescu V, Dequatre N, Leys DHH: Prevalence and determinants of fatigue 1 year after spontaneous intracerebral haemorrhage. Cerebrovasc Dis 2011; 31(suppl):21.

33 Naess H, Lunde L, Brogger J, Waje-Andreassen $\mathrm{U}$ : Fatigue among stroke patients on longterm follow-up. The Bergen Stroke Study. J Neurol Sci 2012;312:138-141.

-34 Winward C, Sackley C, Metha Z, Rothwell PM: A population-based study of the prevalence of fatigue after transient ischemic attack and minor stroke. Stroke 2009;40:757761.

35 Clark USWD: Exercise and the brain; in Cohen RASL (ed): Brain neuroimaging in behavioral medicine and clinical neuroscience. New York, Springer-Verlag, 2010, pp 257 275.

36 Manes F, Paradiso S, Robinson RG: Neuropsychiatric effects of insular stroke. J Nerv Ment Dis 1999;187:707-712.

37 Kutlubaev MA, Mead GE: Letter by Kutlubaev and Mead regarding article, 'Exertion fatigue and chronic fatigue are two distinct constructs in people post-stroke'. Stroke 2011;42:e377.
38 Dishman RK, Berthoud H-R, Booth FW, et al: Neurobiology of exercise. Obesity (Silver Spring) 2006;14:345-356.

39 Meeusen R: Exercise and the brain: insight in new therapeutic modalities. Ann Transplant 2005; 10:49-51.

40 Spalletta G, Ripa A, Caltagirone C: Symptom profile of DSM-IV major and minor depressive disorders in first-ever stroke patients. Am J Geriatr Psychiatry 2005;13:108-115.

41 De Coster L, Leentjens AFG, Lodder J, Verhey FRJ: The sensitivity of somatic symptoms in post-stroke depression: a discriminant analytic approach. Int J Geriatr Psychiatry 2005; 20:358-362.

42 Choi-Kwon S, Choi J, Kwon SU, Kang D-W, Kim JS: Fluoxetine is not effective in the treatment of post-stroke fatigue: a double-blind, placebo-controlled study. Cerebrovasc Dis 2007;23:103-108.

43 Van de Port IGL, Kwakkel G, Schepers VPM, Heinemans CTI, Lindeman E: Is fatigue an independent factor associated with activities of daily living, instrumental activities of daily living and health-related quality of life in chronic stroke? Cerebrovasc Dis 2007;23:4045.

44 Passier PECA, Post MWM, van Zandvoort MJE, Rinkel GJE, Lindeman E, Visser-Meily JMA: Predicting fatigue 1 year after aneurysmal subarachnoid hemorrhage. J Neurol 2011;258:1091-1097.

45 Dimoska-Di Marco A, McDonald S, Kelly M, Tate R, Johnstone S: A meta-analysis of response inhibition and Stroop interference control deficits in adults with traumatic brain injury (TBI). J Clin Exp Neuropsychol 2011; 33:471-485.

46 Ranjith G: Epidemiology of chronic fatigue syndrome. Occup Med (Lond) 2005;55:1319.

47 Lerdal A, Wahl A, Rustøen T, Hanestad BR, Moum T: Fatigue in the general population: a translation and test of the psychometric properties of the Norwegian version of the fatigue severity scale. Scand J Public Health 2005;33: 123-130.

48 Loge JH, Ekeberg O, Kaasa S: Fatigue in the general Norwegian population: normative data and associations. J Psychosom Res 1998; 45:53-65.

49 Andersen G, Christensen D, Kirkevold M, Johnsen SP: Post-stroke fatigue and return to work: a 2-year follow-up. Acta Neurol Scand 2012;125:248-253.

50 Mead G, Bernhardt J, Kwakkel G: Stroke: physical fitness, exercise, and fatigue. Stroke Res Treat 2012;2012:632531.

51 Puchta AE: Why am I so tired after my stroke? J Vasc Interv Neurol 2008;1:63-64.

52 Davies DP, Rodgers H, Walshaw D, James OFW, Gibson GJ: Snoring, daytime sleepiness and stroke: a case-control study of first-ever stroke. J Sleep Res 2003;12:313-318.

53 Hermann DM, Bassetti CL: Sleep apnea and other sleep-wake disorders in stroke. Curr Treat Options Neurol 2003;5:241-249. 
54 Hsu C-Y, Vennelle M, Li H-Y, Engleman HM, Dennis MS, Douglas NJ: Sleep-disordered breathing after stroke: a randomised controlled trial of continuous positive airway pressure. J Neurol Neurosurg Psychiatry 2006;77:1143-1149.

-55 Arnold M, Taylor NF: Does exercise reduce cancer-related fatigue in hospitalised oncology patients? A systematic review. Onkologie 2010;33:625-630.

56 Rasova K, Havrdova E, Brandejsky P, Zálisová $M$, Foubikova $B$, Martinkova P: Comparison of the influence of different rehabilitation programmes on clinical, spirometric and spiroergometric parameters in patients with multiple sclerosis. Mult Scler 2006;12: 227-234.
57 Mostert S, Kesselring J: Effects of a short-term exercise training program on aerobic fitness, fatigue, health perception and activity level of subjects with multiple sclerosis. Mult Scler 2002;8:161-168.

58 Petajan JH, Gappmaier E, White AT, Spencer MK, Mino L, Hicks RW: Impact of aerobic training on fitness and quality of life in multiple sclerosis. Ann Neurol 1996;39: 432-441.
Zedlitz AMEE, Visser-Meily AJMA, Schepers VP, Geurts ACH, Fasotti L: Patients with severe poststroke fatigue show a psychosocial profile comparable to patients with other chronic disease: implications for diagnosis and treatment. ISRN Neurol 2011;2011:627081.

60 Park JY, Chun MH, Kang SH, Lee JA, Kim BR, Shin MJ: Functional outcome in poststroke patients with or without fatigue. Am J Phys Med Rehabil 2009;88:554-558.

61 Broomfield NM, Laidlaw K, Hickabottom E, et al: Post-stroke depression: the case for augmented, individually tailored cognitive behavioural therapy. Clin Psychol Psychother 2011;18:202-217.

-62 Barbour VL, Mead GE: Fatigue after stroke: the patient's perspective. Stroke Res Treat 2012;2012:863031. 